\title{
Effects of Desmethylclozapine on Fos Protein Expression in the Forebrain: In Vivo Biological Activity of the Clozapine Metabolite
}

Cheryl D. Young, Ph.D., Herbert Y. Meltzer, M.D., and Ariel Y. Deutch, Ph.D.

Several products of the hepatic metabolism of clozapine are found in high concentrations in the plasma of schizophrenic patients treated with this atypical antipsychotic drug. One of these metabolites, $N$-desmethylclozapine, has substantially different affinities for dopamine and serotonin metabolites than does the parent compound. However, it is not known if this metabolite is active in vivo. We examined the effect of acute administration of desmethylclozapine to rats on forebrain Fos protein expression. Clozapine induces expression of this immediate-early gene in a distinct regional pattern in the brain. Desmethylclozapine significantly increased Fos protein expression in the medial prefrontal cortex and nucleus accumbens, but not in the dorsolateral striatum, thus mirroring the effects of the parent compound. These data indicate that the desmethyl metabolite of clozapine has in vivo biological activity. [Neuropsychopharmacology 19:99-103, 1998] (C) 1998 American College of Neuropsychopharmacology. Published by Elsevier Science Inc.
KEY WORDS: Antipsychotic drugs; Immediate-early gene; Nucleus accumbens; Prefrontal cortex; Schizophrenia; Striatum

Clozapine is an atypical antipsychotic drug that is effective in the treatment of schizophrenic patients who do not respond to conventional antipsychotic drugs (Kane et al. 1988; Baldessarini and Frankenburg 1991; Meltzer and Ranjan 1996). Clozapine differs from typical antipsychotic drugs (APDs) by lacking any substantial extrapyramidal side effect (EPS) liability, and has been reported to be superior to typical APDs in reducing negative symptoms. The mechanisms that subserve the atypical APD profile of clozapine remain unclear (see Deutch et al. 1991; Fatemi et al. 1996).

From the Departments of Psychiatry and Pharmacology, Vanderbilt University School of Medicine, Nashville, TN 37212.

Address correspondence to: Ariel Y. Deutch, Psychiatric Hospital at Vanderbilt, Suite 313, 1601 23rd Avenue South, Nashville, TN 37212.

Received September 8, 1997; revised November 18, 1997; accepted November 25, 1997.
The metabolism of clozapine is predominantly hepatic, with several metabolites being generated (Fischer et al. 1992; DeVane 1995). The major clozapine metabolites are N-desmethylclozapine and clozapine N-oxide (Centorrino et al. 1994; Pirmohamed et al. 1995). The N-oxide is reduced back to clozapine in the presence of NADPH (Jann et al. 1994). The other major metabolite, desmethylclozapine, is present in plasma concentrations that may exceed $40 \%$ of that of the parent compound in humans (Centorrino et al. 1994). Desmethylclozapine is the major metabolite in the rodent, and serum levels of desmethylclozapine average about $70 \%$ of the parent compound, with brain levels being comparable to serum levels (Baldessarini et al. 1993). Despite the high plasma concentrations of desmethylclozapine in schizophrenic patients receiving clozapine treatment, and the positive correlation between plasma desmethylclozapine concentration and therapeutic outcome (Piscitelli et al. 1994), it remains unclear if this clozapine metabolite has biological activity in vivo (DeVane 1995). Several studies have documented the activity of desmethylclozapine in various in vitro paradigms (Kuoppamaki 
et al. 1993; Gershon et al. 1994; Squires and Saederup 1991), but conclusive evidence of in vivo activity is lacking. This question may have important ramifications for the mechanism of action of clozapine.

Clozapine differs from other APDs by increasing the expression of the immediate-early gene c-fos, or its protein product Fos, in the prefrontal cortex (PFC) (Robertson and Fibiger 1992; Deutch and Duman 1996; see Deutch 1996). Clozapine also increases Fos levels in the shell compartment of the nucleus accumbens (NAS), a site where all APDs are thought to increase Fos expression (Deutch et al. 1992; Robertson et al. 1994; Guo et al. 1995), and in the thalamic paraventricular nucleus (PV) (Deutch et al. 1995). In contrast, clozapine does not increase Fos expression in the dorsolateral striatum, where typical APDs markedly increase Fos expression (Robertson and Fibiger 1992; Deutch et al. 1992; Nguyen et al. 1992). These regionally distinct effects of antipsychotic drugs on Fos expression are seen in both rodent and primate species (Ikemoto et al. 1995; Deutch et al. 1996).

The unique profile of clozapine-induced changes in forebrain Fos expression offers a convenient means of assessing pharmacological effects that are related to the mechanisms of action of clozapine (see Robertson et al. 1994 and Deutch 1996). We therefore used Fos expression as an index of in vivo activity of desmethylclozapine.

\section{MATERIALS AND METHODS}

\section{Animal Treatment}

Adult male Sprague-Dawley rats (Camm; Wayne, NJ) were maintained on a 12:12 light:dark cycle, with food and water available ad libitum. On the test day, rats received subcutaneous injections of desmethylclozapine $(7.5$ or $30.0 \mathrm{mg} / \mathrm{kg})$, clozapine $(7.5$ or $30.0 \mathrm{mg} / \mathrm{kg})$, or $\mathrm{pH}$-matched vehicle, and were killed 2 hours later. The combined infralimbic/prelimbic parts of the PFC were dissected as described previously (Deutch and Duman 1996), as were the NAS, dorsolateral striatum, and thalamic paraventricular nucleus. Samples were stored at $-75^{\circ} \mathrm{C}$ until assayed.

\section{Immunoblot Analyses}

Levels of Fos protein were determined by immunoblots, using a well-characterized antibody that recognizes Fos and several Fos-related antigens (Fras) (Quinn et al. 1989). Western blots were performed on total protein from tissue homogenates of the brain samples. Briefly, the tissues were homogenized in $2 \%$ SDS, and protein levels were determined by the method of Lowry et al. (1951). Equal amounts of protein (for each brain site) were then run on a $10 \%$ acrylamide $/ 0.27 \%$ methylenebisacrylamide gel overnight at $67 \mathrm{~V}$ and transferred to nitrocellulose. Following steps to block nonspecific binding, the blots were incubated overnight at $4^{\circ} \mathrm{C}$ in the primary antibody (1:5000). The next day the blots were washed in blocking buffer, incubated for 2 hours in horseradish peroxidase-conjugated secondary antibody (1:500), and then washed extensively before being developed using chemiluminescence with exposure to Hyperfilm-ECL.

Protein levels were quantitated by measuring band optical densities using computer-assisted densitometry on a Macintosh computer with the public domain NIH Image program (developed at the US National Institutes of Health and available on the Internet at http:/ / rsb.info.nih.gov/nih-image) after calibration on an optical step chart (Kodak). In some cases, depending upon the electrophoretic resolution on the films of the polyacrylamide gels, an apparent doublet was seen at $\approx 55$ $\mathrm{kD}$; this probably represents posttranslational modification of Fos. For the densitometric evaluation of Fos, we measured both bands collectively, because the two species are similarly regulated. Relative optical densities of the Fos bands were assessed; the levels of Fos-related antigens (Fras) were not analyzed, because changes in Fras in response to acute APD treatments remain to be well characterized. The optical densities were compared by means of one-way ANOVAs followed by planned comparisons, with experiment wise $\alpha$ set at 0.05 .

\section{RESULTS}

Acute administration of desmethylclozapine increased Fos protein levels in the PFC and NAS (see Figures 1 and 2); there was also a significant increase in Fos protein levels in the thalamic paraventricular nucleus (data not shown). Neither clozapine nor its metabolite increased Fos expression in the dorsolateral striatum (Figure 1). The effects of desmethylclozapine were dose dependent in the responsive regions. In the PFC, the magnitude of desmethylclozapine-elicited Fos induction appeared to be somewhat greater than that observed after identical doses of clozapine, but this difference was not statistically significant. In contrast, in the NAS, the low dose of clozapine, but not desmethylclozapine, significantly increased Fos expression (see Figure 2 ), as did the high doses of both clozapine and its metabolite. In the PFC and NAS, a band corresponding to Fos is seen in vehicle-treated animals. This band does not appear in the dorsolateral striatum and presumably reflects induction of the protein in response to the stress of the vehicle injection (unpublished observations), which is consistent with the known regionally specific effects of stress on c-fos expression (Cullinan et al. 1995).

\section{DISCUSSION}

These data provide the first demonstration of in vivo biological activity of desmethylclozapine. The effects of desmethylclozapine on Fos protein expression paral- 


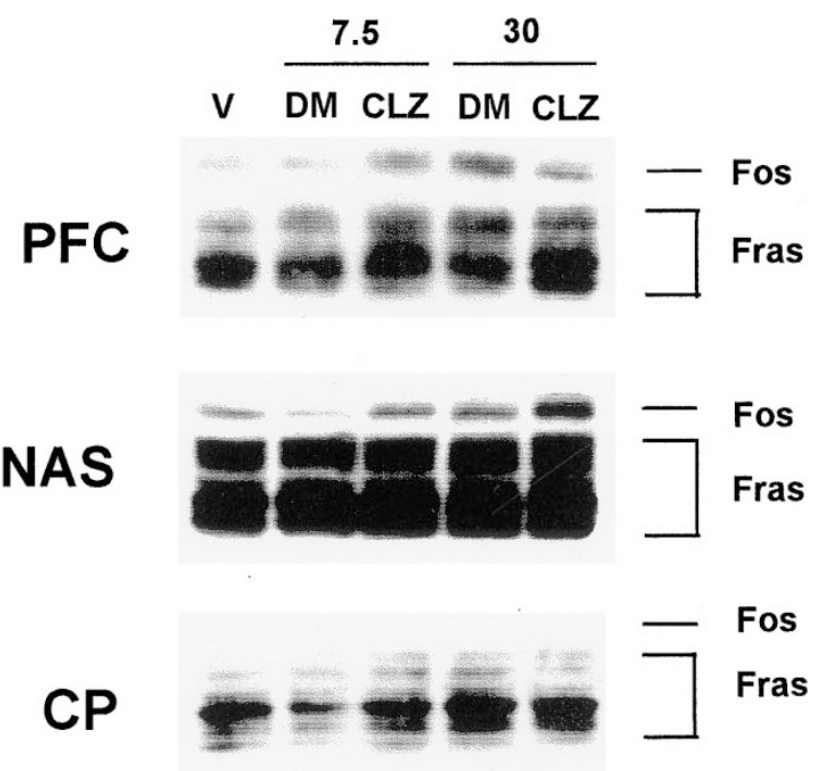

Figure 1. Immunoblots showing the effects of 7.5 or 30 $\mathrm{mg} / \mathrm{kg}$ clozapine (CLZ) and desmethylclozapine (DM) or vehicle $(\mathrm{V})$ on Fos expression in the medial prefrontal cortex (PFC), nucleus accumbens (NAS), or caudatoputamen (CP). Desmethylclozapine and clozapine both increased Fos protein in the PFC and PV, but not in the striatum.

leled those of clozapine: the three brain areas in which clozapine elicited a response also responded to the desmethyl metabolite, whereas the dorsolateral striatum did not respond to either clozapine or its metabolite.

The functional significance of desmethylclozapine in vivo remains unclear. The metabolite may exert therapeutic actions. However, it is plausible that desmethylclozapine is responsible for certain side effects rather than therapeutic actions of clozapine. Desmethylclozapine strongly suppresses hematopoiesis in vitro at concentrations that are lower than those of clozapine and clozapine-N-oxide (Gershon et al. 1994). Because clozapine treatment results in agranulocytosis in about $1 \%$ of patients (Alvir et al. 1993), the suppression of hematopoiesis has fueled speculation that desmethylclozapine is responsible for the clozapine-induced blood dyscrasia. However, subsequent studies examining clozapine and desmethylclozapine plasma levels in patients who developed agranulocytosis failed to support this hypothesis (Hasegawa et al. 1994).

The distinct pattern of Fos induction in response to desmethylclozapine, which faithfully reproduces that seen in response to clozapine challenge, suggests that the metabolite may possess (independently or cooperatively) antipsychotic actions. Previous studies of antipsychotic drugs have revealed that clozapine but not other APDs increases Fos expression in the PFC (Deutch and Duman 1996); both typical and atypical APDs increase Fos protein expression in the nucleus accumbens shell (Deutch et al. 1992; Robertson and Fibiger 1992). The
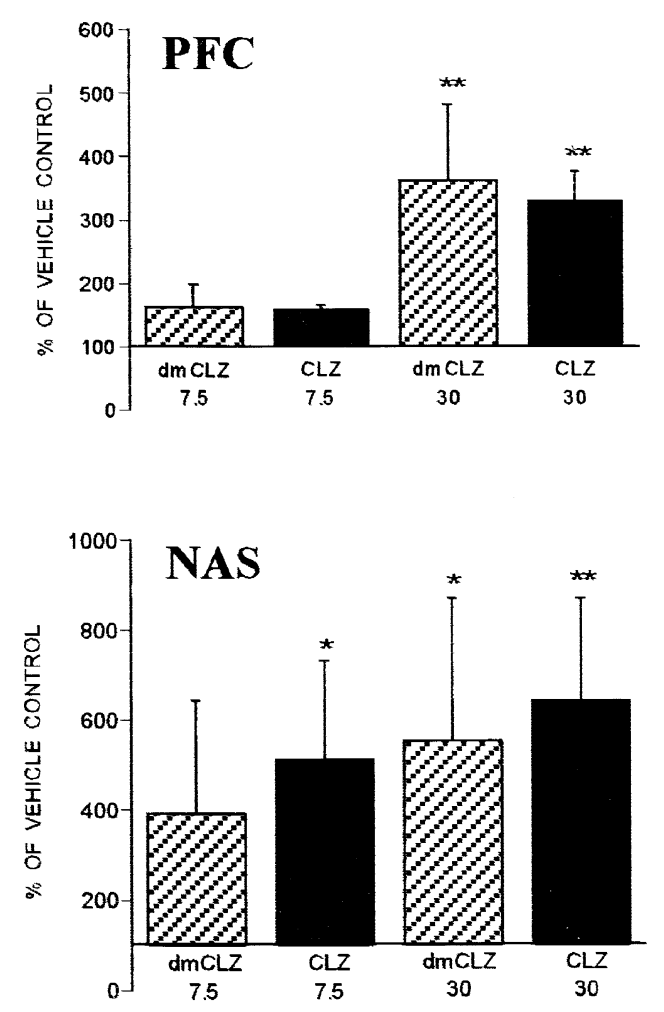

Figure 2. The effects of clozapine (CLZ) and desmethylclozapine (DM) relative to vehicle (V) in the PFC and NAS. The significant increases are relative to vehicle-treated animals; there was no statistically significant difference in the magnitude of the response to clozapine or its metabolite at a given dose. ${ }^{*} p \leqslant .05 .{ }^{* *} p \leqslant .01$.

ability of clozapine to increase Fos in the forebrain has considerable predictive validity for APD actions, and a high degree of convergent validity when compared with several other tests of APD action (see Deutch 1996). It is therefore possible that the ability of desmethylclozapine to induce Fos in selected brain regions reflects antipsychotic efficacy of the clozapine metabolite. This idea fits well with the excellent correlation between plasma levels of desmethylclozapine and reduction in psychotic symptomatology (Piscitelli et al. 1994). Unfortunately, the high correlation between clozapine and its desmethyl and $\mathrm{N}$-oxide metabolites (Centorrino et al. 1994) precludes definitive assessment of the relative contribution of the metabolites to antipsychotic efficacy; to resolve this question would appear to require clinical trials of desmethylclozapine.

Studies of the receptor affinities of desmethylclozapine have so far been restricted to certain serotonergic and dopaminergic receptors. Desmethylclozapine appears to have substantially higher affinities for $\mathrm{D}_{2}$-like receptors (as reflected by $\left[{ }^{3} \mathrm{H}\right]$ spiperone binding) than does clozapine, but shows a reduced affinity for the $D_{1}$ receptor (Kuoppamaki et al. 1993). We are not aware of specific assessments of the affinities of desmethylclozapine for 
the different types of dopamine receptors in the $\mathrm{D}_{1}$ or $\mathrm{D}_{2}$ class. The observation that desmethylclozapine has a higher affinity for $D_{2}$ but lower affinity for $D_{1}$ receptors is congruent with current understanding of the actions of APDs: $\mathrm{D}_{2}$-like receptors clearly have a role in antipsychotic drug action, whereas a recent open trial has suggested that selective $\mathrm{D}_{1}$ receptor antagonists lack therapeutic efficacy (Karlsson et al. 1995).

In addition, desmethylclozapine has higher affinities for the $5-\mathrm{HT}_{2 \mathrm{a}}$ and $5-\mathrm{HT}_{2 \mathrm{c}}$ receptors than the parent compound (Kuoppamaki et al. 1993). These shifts in serotonin receptor affinity parallel those seen in $\mathrm{D}_{2}$ affinity. Thus, desmethylclozapine and its parent compound have approximately the same high ratio of $5-\mathrm{HT}_{2 \mathrm{a}}: \mathrm{D}_{2}$ affinities, a characteristic of APDs that display low EPS liability but continued antipsychotic efficacy (Meltzer et al. 1989). It is interesting to note that the higher affinity of desmethylclozapine for the $\mathrm{D}_{2}$ receptor does not appear to be sufficient to induce Fos in the dorsolateral striatum; this may be due to its increased affinity for the $5-\mathrm{HT} 2_{2 \mathrm{a}}$ receptor, thus maintaining a favorable $5-\mathrm{HT}_{2 \mathrm{a}}: \mathrm{D}_{2}$ profile (Meltzer et al. 1989). Alternatively, it is possible that the lack of striatal Fos expression in response to desmethylclozapine is due to partial occupancy of striatal $\mathrm{D}_{2}$ receptors, as has been reported for clozapine in imaging and postmortem studies (Farde et al. 1992; Hall et al. 1995; Nordstrom et al. 1995).

In summary, the ability of desmethylclozapine to induce Fos protein in selected brain regions provides evidence of the in vivo activity of the clozapine metabolite. Although the functional effects of desmethylclozapine remain unknown, the in vivo activity of the metabolite, coupled with the high plasma concentrations and brain levels, suggests that further attention be devoted to elucidating the functional role(s) of desmethylclozapine.

\section{ACKNOWLEDGMENTS}

We appreciate the generosity of Sandoz in providing clozapine and desmethylclozapine. This work was supported in part by MH-45124 (AYD), MH-57999 (AYD), MH-47808 (HYM), and MH 41684 (HYM).

\section{REFERENCES}

Alvir JM, Lieberman JA, Safferman AZ, Schwimmer JL, Schaaf JA (1993): Clozapine-induced agranulocytosis. Incidence and risk factors in the United States. N Engl J Med 329:162-167

Baldessarini RJ, Frankenburg FR (1991): Clozapine: A novel antipsychotic drug. N Engl J Med 324:746-754

Baldessarini FJ, Centorrino F, Flood JG, Volpicelli SA, HustonLyons D, Cohen BM (1993): Tissue concentrations of clozapine and its metabolites in the rat. Neuropsychopharmacology 9:117-124
Centorrino F, Baldessarini RJ, Kando JC, Frankenburg FR, Volpicelli SA, Flood JG (1994): Clozapine and metabolites: concentrations in serum and clinical findings during treatment of chronically psychotic patients. J Clin Psychopharmacol 14:119-125

Cullinan WE, Herman JP, Battaglia DF, Akil H, Watson SJ (1995): Pattern and time course immediate-early gene expression in rat brain following acute stress. Neuroscience 64:477-505

Deutch AY (1996): The mechanisms of action of antipsychotic drugs as revealed by immediate-early gene expression. In Csernansky JG (ed), Antipsychotics (Handbook of Exp Pharmacol, vol 120). Berlin, Springer, pp 117-161

Deutch AY, Duman RS (1996): The effects of antipsychotic drugs on prefrontal cortical Fos expression: Cellular localization and pharmacological characterization. Neuroscience 70:377-389

Deutch AY, Moghaddam B, Innis R, Krystal JH, Aghajanian GK, Bunney BS, Charney DS (1991): Mechanisms of action of atypical antipsychotic drugs: Implications for novel therapeutic strategies for schizophrenia. Schizophr Res 4:121-156

Deutch AY, Lee MC, Iadorola MJ (1992): Regionally specific effects of atypical antipsychotic drugs on striatal Fos expression: The nucleus accumbens shell as a locus of antipsychotic action. Mol Cell Neurosci 3:332-341

Deutch AY, Öngür D, Duman RS (1995): Fos induction by antipsychotic drugs in the medial thalamus: A novel locus of antipsychotic drug action. Neuroscience 66: 337-346

Deutch AY, Lewis DA, Iadarola MJ, Redmond DE Jr, Roth RH (1996): The effects of $D_{2}$ dopamine antagonists on Fos protein expression in the striatal complex and temporal cortices of the non-human primate. Synapse 23:182-191

DeVane CL (1995): Brief comparison of the pharmacokinetics and pharmacodynamics of the traditional and newer antipsychotic drugs. Am J Health-System Pharm 52 (Suppl): S15-S18

Farde L, Nordstrom AL, Wiesel FA, Pauli S, Halldin C, Sedvall G (1992): Positron emission tomographic analysis of central D1 and D2 dopamine receptor occupancy in patients treated with classical neuroleptics and clozapine. Relation to extrapyramidal side effects. Arch Gen Psychiatry 49:538-544

Fatemi SH, Meltzer HY, Roth BL (1996): Atypical antipsychotic drugs: Clinical and preclinical studies. In Csernansky JG (ed), Antipsychotics (Handbook of Exp Pharmacol, vol 120). Berlin, Springer, pp 77-115

Fischer V, Vogels B, Maurer G, Tynes RE (1992): The antipsychotic clozapine is metabolized by the polymorphic human microsomal and recombinant cytochrome P450 2D6. J Pharmacol Exp Ther 260:1355-1360

Gershon SL, Arce C, Meltzer HY (1994): N-desmethylclozapine: A clozapine metabolite that suppresses haemopoiesis. Br J Haematol 86:555-561

Guo H, Klitenick MA, Tham CS, Fibiger HC (1995): Receptor mechanisms mediating clozapine-induced c-fos expression in the forebrain. Neuroscience 65:747-756 
Hall H, Halldin C, Nyberg S, Farde L, Sedvall G (1995): Effect of clozapine and risperidon on 5-HT2 and D2-dopamine receptor binding in the post-mortem human brain. An autoradiographic study. Eur Neuropsychopharmacol $5: 19-25$

Hasegawa M, Cola PA, Meltzer HY (1994): Plasma clozapine and desmethylclozapine in clozapine-induced agranulocytosis. Neuropsychopharmacology 11:45-47

Ikemoto K, Satoh K, Maeda T, Fibiger HC (1995): Neurochemical heterogeneity of the primate nucleus accumbens. Exp Brain Res 104:177-190

Jann MW, Lam YW, Chang WH (1994): Rapid formation of clozapine in guinea-pigs and man following clozapineN-oxide administration. Arch Int Pharmacodyn Ther 328:243-250

Kane JM, Honigfeld G, Singer J, Meltzer H, and the Clozaril Collaborative Study Group (1988): Clozapine for the treatment-resistant schizophrenic. Arch Gen Psychiatry 45:789-796

Karlsson P, Smith L, Farde L, Harnryd C, Sedvall G, Wiesel FA (1995): Lack of apparent antipsychotic effect of the D1-dopamine receptor antagonist CH39166 in acutely ill schizophrenic patients. Psychopharmacology 121:309316

Kuoppamaki M, Syvalahti E, Hietala J (1993): Clozapine and $\mathrm{N}$-desmethylclozapine are potent $5-\mathrm{HT}_{1 \mathrm{c}}$ receptor antagonists. Eur J Pharmacol (Mol Pharmacol) 245:179-182

Lowry OH, Rosebrough NJ, Farr AL, Randall RJ (1951): Protein measurement with the Folin phenol reagent. J Biol Chem 193:265-275

Meltzer HY, Ranjan R (1996): Efficacy of novel antipsychotic drugs in treatment-refractory schizophrenia. In Csernansky JG (ed), Antipsychotics (Handbook of Exp Pharmacol, vol 120). Berlin, Springer, pp 333-357

Meltzer HY, Matsubara S, Lee J-C (1989): Classification of typical and atypical antipsychotic drugs on the basis of
D-1, D-2, and serotonin $2 \mathrm{pK}_{\mathrm{i}}$ values. J Pharmacol Exp Ther 251:238-246

Nguyen TV, Kasofsky B, Birnbaum R, Cohen BM, Hyman SE (1992): Differential expression of c-fos and Zif 268 in rat striatum following haloperidol, clozapine, and amphetamine. Proc Natl Acad Sci USA 89:4270-4274

Nordstrom AL, Farde L, Nybert S, Karlsson P, Halldin C, Sedvall G (1995): D1, D2, and 5-HT2 receptor occupancy in relation to clozapine serum concentration: A PET study of schizophrenic subjects. Am J Psychiatry 152: 1444-1449

Pirmohamed M, Williams D, Madden S, Templeton E, Park BK (1995): Metabolism and bioactivation of clozapine by human liver in vitro. J Pharmacol Exp Ther 272:984-990

Piscitelli SC, Frazier JA, McKenna K, Albus KE, Grothe DR, Gordon CT, Rapoport JL (1994): Plasma clozapine and haloperidol concentrations in adolescents with childhood onset schizophrenia: association with response. J Clin Psychiatry 55 (Suppl B):94-97

Quinn JP, Takimoto M, Iadarola MJ, Holbrook N, Levens D (1989): Distinct factors bind the AP-1 consensus sites in gibbon ape leukemia virus and simian virus 40 enhancers. J Virol 63:1737-1742

Robertson GS, Fibiger HC (1992): Neuroleptics increase c-fos expression in the forebrain: contrasting effects of haloperidol and clozapine. Neuroscience 46:315-328

Robertson GS, Matsumura H, Fibiger HC (1994): Induction patterns of Fos-like immunoreactivity in the forebrain as predictors of atypical antipsychotic activity. J Pharmacol Exp Ther 271:1058-1066

Squires RF, Saederup E (1991): A review of evidence for GABAergic predominance/glutamatergic deficit as a common etiological factor in both schizophrenia and affective psychoses: More support for a continuum hypothesis of "functional" psychosis. Neurochem Res 16:1099-1111 